\title{
Validity and Reliability of Measurements for Perceived Organizational Support and Turnover Intention Among Employees in the Services Sector
}

Nor Sabrena Norizan, Irzan Ismail, Muhammad Iskandar Hamzah

To Link this Article: http://dx.doi.org/10.6007/IJARBSS/v11-i6/10170 DOI:10.6007/IJARBSS/v11-i6/10170

Received: 01 April 2021, Revised: 28 April 2021, Accepted: 19 May 2021

Published Online: 02 June 2021

In-Text Citation: (Norizan et al., 2021)

To Cite this Article: Norizan, N. S., Ismail, I., \& Hamzah, M. I. (2021). Validity and Reliability of Measurements for Perceived Organizational Support and Turnover Intention Among Employees in the Services Sector. International Journal of Academic Research in Business and Social Sciences, 11(6), 400-409.

Copyright: (c) 2021 The Author(s)

Published by Human Resource Management Academic Research Society (www.hrmars.com) This article is published under the Creative Commons Attribution (CC BY 4.0) license. Anyone may reproduce, distribute, translate and create derivative works of this article (for both commercial and non-commercial purposes), subject to full attribution to the original publication and authors. The full terms of this license may be seen at: http://creativecommons.org/licences/by/4.0/legalcode

Vol. 11, No. 6, 2021, Pg. 400 - 409

Full Terms \& Conditions of access and use can be found at http://hrmars.com/index.php/pages/detail/publication-ethics 


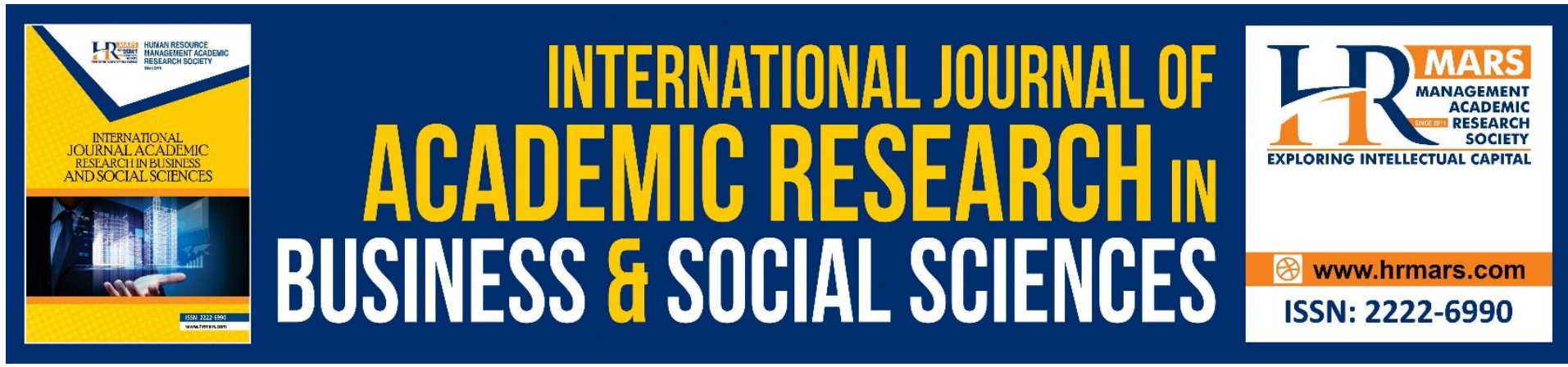

\title{
Validity and Reliability of Measurements for Perceived Organizational Support and Turnover Intention Among Employees in the Services Sector
}

\author{
Nor Sabrena Norizan ${ }^{1}$, Irzan Ismail², Muhammad Iskandar \\ Hamzah $^{3}$ \\ ${ }^{1,2}$ Faculty of Business and Management, Universiti Teknologi MARA, Melaka, ${ }^{3}$ Faculty of \\ Business and Management, Universiti Teknologi MARA, Shah Alam
}

\begin{abstract}
Employee turnover is a major challenge faced by Small and Medium-sized Enterprises (SMEs) in the services sector in Malaysia. It is found that this sector has faced a conservative turnover for the past two years and further studies need to be done to solve this problem. To minimize turnover, employees need to feel safe, valued, and satisfied. Many previous literatures showed that organizations that implement and increase the level of Perceived Organizational Support (POS) among employees could help to overcome turnover problems. Increasing the level of POS is believed to help strengthen the relationship between employee and employer, thereby reducing employees' intention to seek or accept other jobs. This study aims to analyze the validity and reliability of measuring tools designed to identify how POS affects employee turnover in Malaysian SMEs. This study also extends POS research by demonstrating support for a multidimensional measure of supervisor support, organizational justice, and organizational rewards \& work conditions. A quantitative method was used and a pilot test for the reliability of the questionnaires was carried out by using SPSS to examine the results of Cronbach's Alpha. There were 33 respondents from the services sectors who participated in answering the questionnaires. The questionnaire contained 42 -items and was developed after a detailed analysis of the literature. Overall, all components show measuring components under the given component providing a reliable internal consistency measure as the alpha of Cronbach for POS and Turnover Intention ranged from 0.784 to 0.856 .
\end{abstract}

Keywords: Perceived Organizational Support, Turnover Intention, Services Sector, SMEs

\section{Introduction}

SMEs activities were dominated by the services sector, which accounted for 62.4 percent of SMEs and was recognized as one of the economy's most potential sectors and a key player in the coming industrial revolution. In addition, the services sector employs 3.9 million people. Nonetheless, according to ILMIA (2020), the services sector had the highest employee turnover, with an average turnover of $30 \%$, followed by the other services sector 
at 23\%. The rise in Malaysian employee's turnover rate was the main reason why foreign workers were recruited (MEF, 2016).

Improving retention is one way to reduce an organization's costs associated with hiring foreign workers. Therefore, organizations, particularly SMEs, must have wellimplemented strategies and policies that can assist them in improving employee recruitment, increasing retention rates, and increasing employee productivity (McDougall, 2018). The high turnover rate indicates potential retention issues, and more research is needed to determine the causes of such a high turnover rate. The issue of employee turnover should not be taken lightly as it could lead to dire consequences such as job dissatisfaction, lower productivity, increased retaining costs and others. All of these, strain the resources and hinder the growth of the companies. The success of an organization depends upon the support and the contribution of the employees. Studies have shown that turnover is exorbitant (Salleh, Samah \& Anwar, 2017) as turnover can cost two times of current employee's salary due to the organization needs to spend additional money on advertising, recruiting, hiring and training new employees.

The challenges of employee retention have always been discussed by most researchers, academicians, top-level management, as well as Human Resource Specialist, but it is yet to be solved (Wright, 2017). In addition to the new task created due to the changing workforce and technology advancement, yet human skills were still required for the organization to run the technology. Unfortunately, the turnover rate continues to rise, while employee retention rates have begun to fall year after year. The decrease in the rate has made turnover and retention problems more relevant today (Warner, 2018). Sinniah and Kamil (2017) support the notion that the majority of organizations in Asian countries, such as South Korea, Malaysia, Singapore, and Taiwan, currently have a high turnover rate.

Despite the fact that the vast majority of empirical research on employee turnover has been conducted, this issue remains debatable. Irrespective of the support and incentives which were given in retaining employees, the retention strategy was not strong enough implemented by some of the organizations (Juhdi, Pa'Wan \& Hansaram, 2013). Due to the high turnover rate experienced by most organizations among SMEs, particularly in the services sector, it is proposed that this study will suggest potential solutions to these problems. This study intends to fill a knowledge gap by investigating the relationship between POS and turnover intention since most of the past studies were conducted in the western setting. Thus, this study was conducted in Malaysia with the goal of gaining a different perspective.

\section{Literature Review \\ Perceived Organizational Support}

In today's changing workforce, organizations are currently facing difficulties when it comes to attracting and maintaining skilled employees. Over the past few years, challenges such as job uncertainty, merger and acquisition, lack of trust and interest for the mutual wellbeing between employers and employees have been the area of interest by most researchers (Seppänen, 2012). It is found that many employers have yet to completely comprehend the significance of having a positive employee and employer relationship in reducing absenteeism and increasing commitment (Eisenberger, Malone \& Presson, 2016). Many current literatures 
are interested in investigating the effect of POS on several organizational and behavioural outcomes. Research has been shown to use POS alone to predict behaviours such as extrarole behaviour (Rhoades \& Eisenberger, 2002) and withdrawal behaviours such as absenteeism, tardiness and voluntary turnover of employees (Rhoades \& Eisenberger, 2002).

POS was described as the employee's belief that their contributions and well-being are valued by the organization (Eisenberger et al., 1986). The relationship between employees and organization can be strengthened by increasing the level of POS among employees. Employers need to assist the employees in improving this POS to the extent whereas the employees give positive feedback regarding the treatment they obtained from the organization. Employees with a high level of POS will have a high level of affective commitment, increase retention, reducing stress and increase performance as POS is found to has advantage between the relationship of employers and employees (Eisenberger et al., 2016; Kurtessis, Eisenberger, Ford, Buffardi, Stewart \& Adis, 2015; Rhoades \& Eisenberger, 2002). It is proven that the study of POS is one way that can help the organization to create and engage the workforce through the application of well-implemented strategic policies and strategies, which can help the organization to increase the employee's belief and attitudes.

In this study, there were three dimensions of POS used which are supervisor support, organizational justice and organizational rewards \& job conditions. These dimensions were developed by Eisenberger et al. in 1986. These three POS dimensions were used to describe the relationship between individual and organizational support (Aselage \& Eisenberger, 2003; Rhoades and Eisenberger, 2002; Wayne, Shore \& Liden, 1997). The topic of supervisor support has gained a tremendous amount of attention in the literature and is significantly related to turnover and other outcomes in organizations (Rhoades \& Eisenberger, 2002). Based on the organizational support theory, the result revealed a positive relationship between supervisor support and POS (Hutchison, 1997; Malatesta, 1995; Rhoades, Eisenberger \& Emerli, 2001; Yoon, Han \& Sou, 1996; Yoon \& Lim, 1999). Pleasant treatment from colleagues can enhance the positive organizational orientation of a person (Alfisyahri, Etikariena \& Gatari, 2018). In addition, supervisor support can address social and emotional requirements that strongly affect the development of perceived organization support (Kurtessis et al., 2015).

Rhoades and Eisenberger (2002) assert that organizational justice is an important antecedent of POS. The study by Fatt, Khin and Heng (2010) indicated that there is a significant relationship between organizational justice and employee turnover intention. When people feel exposed to injustice, absenteeism and turnover increase and the higher the employee's perception of organizational justice will result in better job satisfaction, commitment and a decrease in turnover (Virgolino, Coelho \& Ribeiro, 2017). Many previous studies have shown that organizational justice contributes to many positive attitudes and behaviours, as employees report less emotional exhaustion and a lower intention to leave (Ambrose \& Schminke, 2009; Colquitt, Scott, Rodell, Long, Zapata, Conlon \& Wesson, 2013; Cole et al., 2010).

Employees expect appropriate rewards and recognition for their contributions to the organization through organizational rewards \& job conditions, which are significant dimensions of POS (Shore $\&$ Shore, 1995). According to research on organizational rewards 
\& job conditions, these two variables have a negative relationship with turnover intention (Kim \& Stoner, 2008; Luna-Arocas \& Camps, 2007; Dane \& Brummel, 2014). As a result, it is agreed that when organizations value their employees' contributions, employees will be more willing to perform at a higher level, which will have a strong impact on POS (Eisenberger et al., 1986; Shore \& Shore, 1995).

\section{Turnover Intention}

This study focuses on the effect of POS on turnover intention. Turnover intention is an employee psychological response where employees intend to leave the organization for another (Aliyu \& Nyadzayo, 2018). Turnover is a major problem for the services sector in Malaysia due to the high turnover experienced by this sector in 2018 and 2017 (ILMIA, 2020). As a result, the organization usually looks at the monetary and non-monetary costs of turnover, including the need for the organization to spend additional costs on recruitment, recruitment, training of new staff when employees leave the organization (Bonds, 2017). In addition, employee turnover is found to significantly impact organizational performance, productivity, and commitment (Bonds, 2017).

\section{Perceived Organizational Support and Turnover Intention}

The general negative relationship has been well established between POS and withdrawal behaviour, retention and turnover intention (Rhoades \& Eisenberger, 2002). According to Krishnan and Mary (2012), POS has a significant impact on employee turnover. It has been discovered that such POS is significantly related to employees' well-being, and as a result, employees will develop a more positive attitude toward the organization and behavioural outcomes (Allen, Shore and Griffeth, 2003; Eisenberger, Fasolo \& DavisLaMastro, 1990; Rhoades \& Eisenberger, 2002). Kurtessis et al. (2015) discovered that POS was negatively related to turnover intention in their meta-analytical assessment of the Organizational Support Theory. Employees with a high POS are more engaged and committed, more satisfied with the organization's mission and vision, and less likely to leave.

\section{Theoretical Framework}

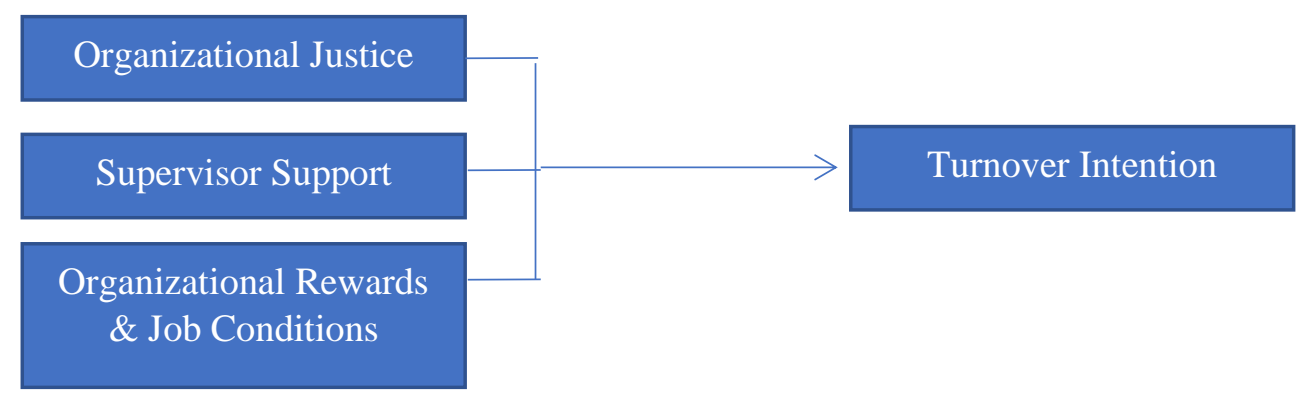

Adapted from: Eisenberger et al. (1986), Rhoades and Eisenberger (2002)

\section{Research Methodology}

The study was conducted by using a quantitative approach, via questionnaire method. A total of 33 employees working in lower, middle and upper-level management in the services sector except for the owner of the SMEs in Peninsular Malaysia were randomly selected for this pilot study. According to Isaac and Michael (1995), the appropriate number of pilot test respondents in the survey questionnaire is between 10 and 30 respondents. Peninsular Malaysia has been selected due to the high percentage of SMEs establishment in Peninsular 
Malaysia with $86.8 \%$ as compared to Sabah and Sarawak $13.2 \%$. The chosen employees were asked to answer the questions related to their knowledge regarding POS and turnover intention. The survey questionnaires consist of three sections. In the first section, the respondents were asked regarding their demographic profile that is related to their age, gender, education level, position, number of years they had served in their current position and salary.

In the second section, the respondents were asked questions related to POS. The questions related to supervisor support (i.e. my supervisor really cares about my well-being and my supervisor is willing to help me to perform my job to the best of my ability), organizational justice (i.e. my organization would not replace me even when they could find someone at a much lower salary and my organization appreciates any extra effort from me) organizational reward \& job conditions (i.e. my organization values my contribution to its well-being and my organization provides me with the opportunity to move up the ranks) were asked to identify factors that make them stay. The measurement of POS was adapted from the 36-item Survey of POS developed by Eisenberger et al. (1986). The original scale of POS was unidimensional and had high internal reliability. However, for the purpose of this study, the researcher develops a multidimensional conceptualization of POS consisting of supervisor support, organizational justice and organizational rewards \& job conditions. The 7-point Likert-scale format $(0=$ Strongly Disagree, $6=$ Strongly Disagree) was used to indicate the respondent's response towards the statement given.

The final section of the survey questionnaires asks respondents how far they will stay at the organization. The measurement of turnover intention consists of a 6 -item survey and adopted from Spector, Dwyer and Jex (1988), Lawler, Cammann, Nadler dan Jenkins (1975) and Roodt (2004). The scale ranges from 1 to 7 (strongly disagree).

\section{Content Validity}

Content validity pertains to the degree to which the instrument fully assesses or measures the construct of interest (Kumar, Abdul Talib \& Ramayah, 2013). It occurs when the experiment provides adequate coverage of the subject being studied. In this study, the questions were adopted from past researchers. An industry expert panel was contacted to confirm the measurement tool and asked to provide feedback on how well each question measures in the question. The expert assessed the appropriateness, meaningfulness, usefulness and effectiveness of each question to determine how accurately the measuring tool taps the various aspects of the construction questions.

\section{Reliability}

A pilot test is performed to detect weaknesses in the questionnaire design and instrumentation and to provide proxy data for a probability sample selection process. Therefore, it should draw subjects from a target population and stimulate the procedures and protocols for data collection. Depending on the method to be tested, the pilot group may range from 25 to 100 subjects (Cooper \& Schindler, 2014). The data obtained from the pilot study were analyzed using SPSS and the method used was calculated using the Cronbach Alpha Coefficient. The tools to analyze the data in this study were POS (supervisor support, organizational justice and organizational rewards \& job conditions).

\section{Findings}

In this study, the pilot test was distributed conveniently among 33 employees in the services 
sector. The results of this study have been assessed using Cronbach Alpha reliability. A pilot study is important as it helps to ensure that the research is done properly before the actual survey can be conducted. The Cronbach Alpha score of each construct was presented in Table 1 below.

Table 1: Cronbach Alpha Score

\begin{tabular}{|l|l|l|}
\hline Constructs & Items & Cronbach's Alpha \\
\hline Supervisor Support & 9 & 0.856 \\
\hline Organizational Justice & 17 & 0.894 \\
\hline Organizational Rewards and Job Conditions & 10 & 0.894 \\
\hline Turnover Intention & 6 & 0.784 \\
\hline
\end{tabular}

The table above shows the reliability analysis of POS and turnover intention. The Cronbach Alpha shows the alpha ranges from 0.784 to 0.894 , which indicates the instrument has high reliability. The reliability score for each instrument is 0.856 for supervisor support, 0.894 for organizational justice and organizational rewards \& job conditions and 0.784 for turnover intention. A reliability score can range from 0.00 to 1.00 and a higher score represent a higher level of reliability (Kimberlin \& Winsterstein, 2008). In this study, the reliability is greater than 0.7 , which is the threshold usually used for reliability and can continue to the next level of the research (Fornell \& Larcker, 1981). It can be concluded that all constructs have satisfactory internal consistency reliability.

\section{Discussion}

This study aims to analyze the validity and reliability of measuring tools designed to identify how POS affects employee turnover in Malaysian SMEs. Reliability testing is very important in this study as the researcher wants to ensure consistency and stability of multidimensional conceptualization of POS developed as the original scale developed by Eisenberger et al. in 1986 was unidimensional. To determine the reliability of the questionnaire, the researcher used the Cronbach Alpha value. The result has shown that the three variables of POS are suitable for use in research conducted by the researchers in determining the effect of POS on the turnover intention of Small and Medium-sized Enterprises in Peninsular Malaysia. The Cronbach Alpha values between the three dimensions of the POS was between 0.856 and 0.894 and it can be concluded that the reliability index questionnaire instrument is high and acceptable at its level of reliability.

\section{Conclusion}

After testing the POS instrument's reliability and validity, it was determined that these measurements are deemed appropriate for measuring the impact of POS and turnover intention among employees in the services sector. Furthermore, the high-reliability value of the measurements can be used to assess the organization's support for its employees in terms of organizational justice, supervisor support, and organizational rewards and job conditions. These three antecedents can serve as a guideline for the organization in lowering the turnover and increase the retention rate among employees in the services sector. Since this is a pilot study, it is hoped that these measurement can be used as a reference to guide future POS research, as research on multidimensional POS instruments is still in an infant stage. 


\section{Acknowledgement}

This research is funded under the Fundamental Research Grant Scheme (600-IRMI/FRGS 5/3 (147/2019). Therefore, the authors wish to express their gratitude for the financial support given for this research to the Ministry of Education and Universiti Teknologi MARA, Malaysia. The funders did not have a role in the design of this study, data collection and analysis, decision to publish or prepare a manuscript.

\section{References}

Aliyu, O. A., \& Nyadzayo, M. W. (2018). Reducing Employee Turnover Intention: A Customer Relationship Management Perspective. Journal of Strategic Marketing, 26 (3), 241257.

Allen, D. G., Shore, L. M., \& Griffeth, R. W. (2003). The Role of Perceived Organizational Support and Supportive Human Resource Practices in the Turnover Process. Journal of Management, 29 (1), 99-118.

Ambrose, M. L., \& Schminke, M. (2009). The Role of Overall Justice Judgments in Organizational Justice Research: A Test of Mediation, Journal of Applied Psychology, 94 (2), 491-500.

Alfisyahria, K., Etikarienab, A., and Gatarib, E. (2018) The Relationship between Perceived Organizational Support and Employers Turnover Intention through Supportive CoWorker Workshop in Division B at Company X, Advances in Social Science, Education and Humanities Research, 135, 464-474.

Aselage, J., \& Eisenberger, R. (2003). Perceived Organizational Support and Psychological Contracts: A Theoretical Integration. Journal of Organizational Behavior, 24, 491-509.

Bond, A. A. (2017). Employees' Organizational Commitment and Turnover Intentions. (Unpublished doctoral dissertation). Waldern University, United States.

Cole, M. S., Bernerth, J. B., Walter, F., and Holt, D. T. (2010). Organizational Justice and Individuals' Withdrawal: Unlocking the Influence of Emotional Exhaustion. Journal of Management Studies, 47 (3), 367-390.

Colquitt, J. A., Scott, B. A., Rodell, J. B., Long, D. M., Zapata, C. P., Conlon, D. E. and Wesson, M. J. (2013). Justice at the Millennium, a Decade Later: A Meta-Analytic Test of Social Exchange and Affect Based Perspectives. Journal of Applied Psychology, 98 (2), 199236.

Cooper, D. R., \& Schindler, P. S. (2014). Business Research Methods. United States: McGraw Hill.

Dane, E., \& Brummel, B. J. (2014). Examining Workplace Mindfulness and Its Relations to Job Performance and Turnover Intention. Human Relations, 67 (1), 105-128.

Eisenberger, R., Huntington, R., Hutchinson, S., \& Sowa, D. (1986). Perceived Organizational Support, Journal of Applied Psychology, 71, 500-507.

Eisenberger, R., Fasolo, E. M. \& Davis-LaMastro, V. (1990). Effects of Perceived Organizational Support on Employee Diligence, Innovation and Commitment. Journal of Applied Psychology, 53, 51-59.

Eisenberger, R., Malone, G. P., \& Presson W. D. (2016). Optimizing Perceived Organizational Support to Enhance Employee Engagement, 1-22, Retrieved from https://www.shrm.org/hr-today/trends-and-forecasting/special-reports-and-expertviews/Documents/SHRM-SIOP\%20Perceived\%200rganizational\%20Support.pdf

Fatt, C. K., Khin, E. W. S., \& Heng, T. N. (2010). The Impact of Organizational Justice on Employee's Job Satisfaction: The Malaysian Companies Perspectives. American 
Journal of Economics and Administration, 2 (1), 65-72.

Fornell, C., \& Larcker, D. F. (1981). Structural Equation Models with Unobservable Variables and Measurement Error: Algebra and Statistics. Journal of Marketing Research, 18 (3), 382-388.

Hutchison, S. (1997). A Path Model of Perceived Organizational Support. Journal of Social Behavior and Personality, 12 (1), 159-174.

Institute of Labour Market Information and Analysis (ILMIA). (2020). Retrieved from Ministry of Human Resources. https://www.ilmia.gov.my/ebook/research/ILMIA_ArtcFREP1_2019_NER2018.pdf

Isaac, S., \& Michael, W. B. (1995). Handbook in Research and Evaluation. San Diego, CA: Educational and Industrial Testing Services.

Juhdi, N., Pa'Wan, F., \& Hansaram, M. K. (2013). HR Practices and Turnover Intention: The Mediating Roles of Organizational Commitment and Organizational Engagement in a Selected Region in Malaysia. The International Journal of Human Resource Management, 1-18.

Kim, H., \& Stoner, M. (2008). Burnout and Turnover Intention among Social Workers: Effects of Role Stress, Job Autonomy and Social Support. Administration in Social Work, 32 (3), 5-25.

Kimberlin, C. L., \& Winterstein, A. G. (2008). Validity and Reliability of Measurement Instruments Used in Research. American Journal Health System Pharmacy, 65, 22762284.

Krishnan, J., \& Mary, V. S. (2012). Perceived Organizational Support: An Overview on its Antecedents and Consequences. International Journal of Multidisciplinary Research, 2 (4), 2-3.

Kumar, M., Abdul Talib, S., \& Ramayah, T. (2013). Business Research Methods. Kuala Lumpur: Oxford University Press.

Kurtessis, J. N., Eisenberger, R., Ford, M. T., Buffardi, L. C., Stewart, K. A., and Adis, C. S. (2015). Perceived Organizational Support: A Meta-Analytic Evaluation of Organizational Support Theory. Journal of Management, 1-31.

Lawler, E., Cammann, C., Nadler, D., \& Jenkins, D. (1975). Michigan Organizational Assessment Questionnaire Database.

Luna-Arocas, R., \& Camps, J. (2007). A Model of High Performance Work Practices and Turnover Intentions. Personnel Review, 37 (1), 26-46.

Malatesta, R. M. (1995). Understanding the Dynamics of Organizational and Supervisory Commitment Using A Social Exchange Framework. Unpublished doctoral dissertation, Wayne State University

McDougall, J. (2018). What Is Employee Retention And What Factors Contribute To It? Retrieved from https://business.dailypay.com/blog/employee-retention

MEF (Malaysian Employers Federation). (2016). Employers Grant Lower Salary Increases and Bonuses. MEF Press Release. Retrieved on May 20, 2020, from http://www.mef.org.my/news

Rhoades, L., Eisenberger, R., \& Armeli, S. (2001). Affective Commitment to the Organization: The Contribution of Perceived Organizational Support. Journal of Applied Psychology, $86,825-836$.

Rhoades, L., \& Eisenberger, R. (2002). Perceived Organizational Support: A Review of the Literature. Journal of Applied Psychology, 87 (4), 698-714.

Roodt, G. (2004). Turnover intentions. Unpublished document. University of Johannesburg. 
Salleh, L. M., Abu Samah, B., and Anwar, M. A. (2017). Leader Attributes and Effect on Loyalty among Malaysian Generation $Y$ Public Administrators. Malaysian Management Review, 52 (1), 63-72.

Seppänen, A. (2012). Perceptions of Perceived Organizational Support and Affective Organizational Commitment in Radisson Blue Seaside. (Unpublished Degree Thesis). University of Applied Sciences.

Shore, L. M., \& Shore, T. H. (1995). Perceived Organizational Support and Organizational Justice. In R. S. \& K. M. Kacmar (Eds.), Organizational Politics, Justice and Support: Managing the Social Climate of the Workplace (149-164). Westport, CT: Quorum.

Sinniah, S., \& Kamil, N. M. (2017). The Influence of Human Resource Practices on Turnover Intention: The Case of a Telecommunication Company in Malaysia, Malaysia Management Review, 52 (1), 1-78.

Spector, P. E., Dwyer, D. J., \& Jex, S. M. (1988). Relation of Job Stressors to Affective, Health, and Performance Outcomes: A Comparison of Multiple Data Sources. Journal of Applied Psychology, 73 (1), 11-19.

Virgolino, A. I., Coelho, A., and Ribeiro, N. (2017). The Impact of Perceived Organizational Justice, Psychological Contract, and the Burnout on Employee Performance: The Moderating Role of Organizational Support, in the Portuguese Context. International Journal of Academic Research in Business and Social Sciences, 7 (1), 241-263.

Wayne, S. J., Shore, L. M., and Liden, R. C. (1997). Perceived Organizational Support and Leader-Member Exchange: A Social Exchange Perspective. Academy of Management Journal, 40 (1), 82-111.

Warner, J. (2018). Four Reasons Why Employee Retention Is a Challenge, Retrieved from https://decision-wise.com/employee-retention-is-challenging/

Wright. (2017). Employers Face Skill And Talent Shortage Challenge. The Star. Retrieved from https://www.thestar.com.my/business-news/2017/03/11/employers-face-skilland-talent-shortage-challenge.। 